INTERNATIONAL JOURNAL OF PUBLIC DEVOTION

e-ISSN: 2614-6762 dan p-ISSN: 2614-6746

Volume 3 Number 1 . July 2020

(c) (i) ()) This work is licensed under

a Creative Commons Attribution-NonCommercial 4.0 International License.

\title{
Teknologi Saringan Air Berbahan Pasir Kerubung di Pondok Pesantren Tarbiyah Islamiyah Singkawang
}

\author{
Riski Muliyani ${ }^{1}$, Yudi Kurniawan ${ }^{2}$, Iip Istirahayu ${ }^{3}$ \\ Pendidikan Fisika/ STKIP Singkawang ${ }^{1,2}$, Bimbingan Konseling/ STKIP Singkawang ${ }^{3}$ \\ kikiriski1012@gmail.com ${ }^{1}$, yudikurniawan1012@gmail.com², \\ iip_istirahayu@yahoo.com ${ }^{3}$
}

Kata Kunci:

Teknologi, saringan; air; pasir kerubung, Pondok Pesantren Tarbiyah Islamiyah

\begin{abstract}
ABSTRAK
Tujuan diadakannya pengabdian ini ialah menerapkan teknologi saringan air menggunakan pasir kerubung. Program pengabdian ini dipilih dikarenakan buruknya kualitas air (air keruh, berwarna merah-kecoklatan) yang dipakai untuk kebutuhan sehari-hari warga pondok pesantren selaku mitra pengabdi. Metode yang dipakai dalam pengabdian ini ialah pengidentifikasian, perencanaan, instalasi, dan pengujian. Teknis intalasi air yang dipakai berupa metode saringan air lambat. Komposisi saringan metode air lambat dengan pasir kerubung menggunakan proporsi 15: 4: 4:1 dengan jenis bahan berturut-turut pasir kerubung, pasir zeolite, karbon aktif dan ijuk. Hasil yang diperoleh ialah warna air menjadi bening, dengan TDS 8 ppm dan $p H=7$. Secara kualitatif, terjadi transfer pengetahuan keterampilan perancangan saringan dari tim pengabdi kepada tim mitra PKM dalam membuat saringan air. Berdasarkan hasil tersebut, dapat disimpulkan bahwa penerapan teknologi saringan air berbahan pasir kerubung berhasil menjernihkan sumber air dan meningkatkan kualitas air di lokasi mitra (Pondok Pesantren Tarbiyah Islamiyah.)
\end{abstract}

Keywords:

Water purification; design; kerubung sand, Pondok Pesantren Tarbiyah Islamiyah

\section{ABSTRACT}

The purpose of this service program is to apply water filter technology by using the Kerubung sand. This service program was chosen due to the poor quality of water (cloudy water, red-brown in color) which is used for the daily needs of the boarding school residents as service program partners. The method used in this service was identification, planning, installation, and testing. The water installation technique used was a slow water filter method. The filter composition of the slow water method with Kerubung sand uses proportion of 15: 4: 4: 1 with the types of materials such as Kerubung sand, zeolite sand, activated carbon and palm fiber. The results obtained were that the color of the water became clear, with a TDS of 8 
ppm and $p H=7$. Qualitatively, there was a transfer of knowledge of filter design skills from the service team to the PKM partner team in making water filters. Based on these results, it can be concluded that the application of water filter technology made from Kerubung sand has succeeded in the purifying water sources and improving the quality of water at the partner location (Pondok Pesantren Tarbiyah Islamiyah).

\section{PENDAHULUAN}

Kebutuhan air bersih merupakan prioritas dalam berbagai jenjang level sosial kemasyarakatan terutama di kota-kota besar atau pusat kecamatan cenderung mengalami peningkatan yang sangat signifikan. Hal ini dikarenakan terjadinya pemusatan kepadatan penduduk sehingga kebutuhan air bersih menjadi permasalahan sosial baru selain kemiskinan (Fatma, 2018; Handarsari et al., 2017; Kristianto et al., 2017). Permasalahan tersebut juga terjadi di Kota Singkawang dimana Tim Pengabdi dari STKIP Singkawang melakukan proses pengabdian di Pondok Pesantren Tarbiyah Islamiyah Singkawang (PPTI).

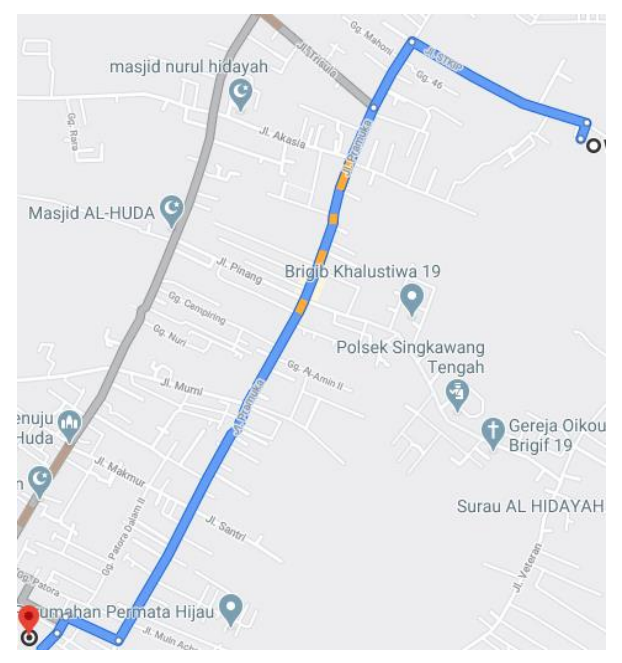

Gambar 1. Lokasi Mitra PkM

Sumber air bersih yang tersedia di dalam PPTI melalui sumur gorong-gorong dan sumur bor belum cukup untuk memenuhi kebutuhan air bersih seluruh warga pondok. Para penghuni pondok sebelumnya telah berupaya menyaring air sumur agar layak pakai namun hasilnya masih tetap berwarna kuning kecoklatan dan cenderung berbau bahkan pada saat tim pengabdi melakukan survey lapangan ditemukan bahwa penyaring satu-satunya yang dimiliki sudah rusak. Dengan demikian, dapat disimpulkan bahwa air sumur yang diambil menggunakan timba langsung dipakai untuk aktivitas sehari-hari warga pondok tanpa disaring terlebih dahulu. Dampaknya, kesehatan warga pondok banyak terganggu khususnya keluhan gangguan pada kulit (Handarsari et al., 2017; Kristianto et al., 2017; Kusumawardani \& Astuti, 2019; Makmudah \& Notodarmojo, 2010; Nainggolan et al., 2017; Salim et al., 2018). Oleh karena itu, tim Pengabdi dari STKIP Singkawang melakukan proses pengabdian di Pondok Pesantren Tarbiyah Islamiyah Singkawang (PPTI).

Desain saringan air yang dirancang oleh tim pengabdi merupakan suatu alternatif solusi untuk mencukupi kebutuhan air bersih di pondok pesantren. Desain ini dibuat menggunakan bahan-bahan yang tersedia di area Kota Singkawang sehingga mudah di dapatkan jika harus dilakukan perawatan berkala. Dalam mendukung upaya keberlangsungan proses desain saringan yang telah dibuat, pengabdi berupaya menyediakan pedoman susunan komponen penyaring menggunakan bahan-bahan 
local sehingga dapat dijadikan acuan bagi warga pondok PPTI untuk menjaga kualitas saringan dan daya tahan alat penyaring. Kualitas air yang baik juga ditentukan dengan kondisi bahan penyaring sehingga perawatan menjadi penting (Fatma, 2018; Handarsari et al., 2017; Kristianto et al., 2017; Sugiarto \& Suharwanto, 2017).(Sugiarto \& Suharwanto, 2017) Dengan kata lain, proses desain dilakukan oleh pengabdi dan proses perakitan akan dilakukan oleh warga PPTI didampingi oleh tim pengabdi.

Luaran yang diharapkan dari proses pengabdian ini ialah terciptanya suatu desain alat penyaring yang handal untuk menyaring air sehingga memenuhi kebutuhan air bersih bagi warga PPTI dengan indikator tidak berwarna (bening), tidak berbau, dan hasil klinis berupa turbiditas dan derajat keasaman. Selain itu, luaran tambahan desain saringan air yang dirancang oleh tim pengabdi akan diajukan untuk kepemilikan HKI dengan status granted (terbit).

\section{METODE PELAKSANAAN}

Proses desain dimulai pada akhir Maret 2020 dimana pada saat itu seluruh provinsi di Indonesia sedang berjuang untuk memutus penyebaran rantai pandemic Covid-19. Oleh karena itu, tim pengabdi berbagi tugas untuk melakukan survey alat dan bahan sehingga dapat meminimalkan waktu di luar rumah. Terkumpulnya data alat dan bahan yang diperlukan untuk merealisasikan program tidak serta merta membuat tim pengabdi leluasa melakukan aktivitas di lokasi mitra. Dengan berlakunya Pembatasan Sosial Skala Besar (PSBB) oleh Pemerintah Pusat maka seluruh daerah (termasuk lokasi tim Pengabdi dan lokasi mitra) meniadakan kerumunan masyarakat atau aktivitas yang dapat mengundang/ menyebabkan terjadinya kerumunan masyarakat. Proses pelaksanaan program pengabdian khusus instalasi saringan dilakukan bulan Juli 2020 di lokasi mitra (Pondok Pesantren Tarbiyah Islamiyah/ PPTI).

Metode yang dipakai dalam mendesain saringan air ialah menggunakan literatur review. Seluruh artikel yang dipelajari adalah yang berfokus pada penyaringan dengan metode saringan air lambat. Hal ini dipilih oleh pengabdi dikarenakan terdapat kesesuaian dengan metode kerja saringan yang direncanakan untuk dikembangkan oleh tim pengabdi. Tim pengabdi mengambil rujukan dari berbagai literatur untuk menentukan komposisi terbaik untuk menghasilkan saringan air yang mampu menjernihkan air sumur menjadi bening dan tidak berbau. Komposisi material penyaring air dengan menggunakan berbagai bahan diantara zeolite, karbon aktif, dan ijuk juga menentukan kualitas hasil saringan(Andrie et al., 2016; Fatma, 2018; Kusumawardani \& Astuti, 2019; Quddus, 2104; Sampurno et al., 2015; Sugiarto \& Suharwanto, 2017). Sebagai hasil akhir, pengabdi mengembangkan komposisi tersendiri sehingga dapat diajukan sebagai HKI untuk teknis penyusunan, pengisian, perawatan penyaring air. Desain lapisan saringan dibatasi oleh lapisan ijuk untuk membatasi antar komponen selain itu sehingga mudah dibersihkan.

Untuk pelaksanaan program, digunakan ialah identifikasi, perencanaan, instalasi, dan pengujian. Proses identifikasi oleh pengabdi ialah menentukan factor pendukung dan poenghambat program di lapangan, sumber-seumber air di lokasi mitra serta komposisi alat dan bahan. Hasil dari proses identifikasi ini ialah desain saringan pada Gambar 3.

Tahapan selanjutnya, Perencanaan. Proses ini sudah meliputi teknis rencana pembelian material penyaring beserta jumlah yang dibutuhkan. Susunan mataerial yang dipakai terdiri dari pasir kerubung, ijuk, karbon aktif, pasir zeolite. Proses instalasi susunan material ialah pasir kerubung, zeolite, karbon aktif dan ijuk dengan perbandingan 15: 4: 4: 1. Pada tahap selanjutnya, dilakukan pengujian kualitas air hasil saringan. Hasil saringan diuji secara klinis yaitu menguji tingkat kekeruhan air (turbiditas) dan derajat keasaman air (ph air). 


\section{HASIL DAN PEMBAHASAN}

Berdasarkan hasil pengabdian yang telah dilakukan maka secara umum dapat disimpulkan bahwa program pengabdian ini berhasil menyaring sumber air kotor di pondok pesantren Tarbiyah Islamiyah di Kota Singkawang dengan hasil saringan menjadi bersih, bening, dan tidak berbau. Adapun hasil kilinis menunjukkan turbiditas $=8 \mathrm{ppm}$ dan $\mathrm{pH}$ air $=7$. Secara ringkas, hasil saringan dapat dilihat pada Gambar 2.

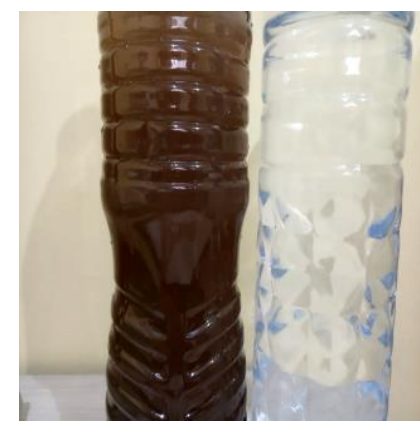

Gambar 2. Perbandingan kualitas air sebelum dan sesudah disaring

Adapun komponen penyaring yang dipakai ialah pasir kerubung, pasir zeolite, karbon aktif, dan ijuk dengan proporsi berturut-turut ialah 15: 4: 4: 1. Komposisi ini disesuaikan dengan kondisi kekeruhan air. Jika dianalisis lebih lanjut bahwa proporsi terbesar dari isi penyaring air ialah adalah komposisi pasir kerubung diantara komponen saringan lainnya. Secara ringkas, susunan saringan dapat dilihat pada Gambar 3 .

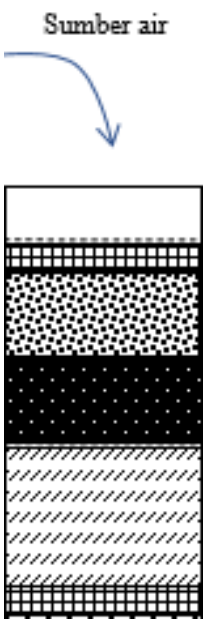

Gambar 3. Sketsa susunan komponen saringan level-1

Jika merujuk pada Gambar 3, maka dapat terlihat bahwa gravitasi memegang peranan penting dalam metode saringan air lambat. Proses jatuhnya air bergerak secara alamiah dipengaruhi oleh gravitasi(Andrie et al., 2016; Fatma, 2018; Sugiarto \& Suharwanto, 2017). Sumber air yang dimiliki/ tersedia di daerah pondok dipompa ke atas penyaringan, kemudian di dalam saringan akan melewati lapisan demi lapisan sehingga pada bagian bawah nanti akan dialirkan menuju ke kamar mandi/ tempat penampungan bak hasil saringan. Jika diperhatikan lebih rinci, terdapat ruang kosong antara mulut wadah terluar penyaring dengan lapisan komponen pertama. Hal ini dimaksudkan untuk memperpanjang waktu kontak antara air dengan komponen penyaring sehingga memperbesar kuantitas kotoran yang tertahan di lapisan saringan. Oleh karena itu, susunan komponen filter dimulai dari yang menghasilkan celah paling renggang menuju yang paling rapat yaitu ijuk, pasir zeolite, arang, dan pasir kerubung. Proses pengendapan ini terjadi diantara rongga butir pasir sehingga terikat oleh gaya adhesi antara partikel pasir dengan kotoran (Makmudah \& Notodarmojo, 2010). Jika dipandang melalui aspek fisis, celah antar partikel pasir (baik pasir kerubung maupun pasir zeolite) harus dibuat sedemikian rupa agar endapan/ kotoran mampu terikat/ tersangkut sehingga setiap lapisan mampu menahan kotoran dengan ukuran yang berbeda-beda. 
Pada lapisan pertama, desain dibuat dengan meletakan ijuk sebagai filter pertama diikuti oleh zeolite, karbon aktif, dan pasir kerubung. Pasir bermanfaat untuk menjadi bantalan halus yang hampir sempurna proses filternya serta pasir zeolite yang dipilih pengabdi dikarenakan tidak mengubah $\mathrm{pH}$ dan mampu mengikat kandungan kapur pada air (Istiqomah, 2014). Kadar besi dan mangan dalam air diserap oleh karbon aktif sehingga hasil saringan diharapkan menjadi lebih bersih. Fungsi lainnya ialah menyerap acun dan bau yang terkandung di dalam air (Salim et al., 2018; Sumekar \& Febriani, 2019).

Program ini dibuat Bersama antara tim pengabdi dengan tim mitra sehingga mitra dapat merasakan secara langsung manfaat yang diberikan tim pengabdi melalui program penyaringan air ini. Secara ekonomis, warga Pondok Pesantrn Tarbiyah Islamiyah (PPTI) Singkawang mampu menggunakan air bersih untuk keperluan sehari-hari secara langsung sehingga biaya pembelian air dapat dialihkan pada pos yang lain. Manfaat secara social, selain terjalinnya komunikasi dan Kerjasama antara tim pengabdi dengan tim mitra (PPTI Singkawang), program ini mampu meberikan pengatahuan dan pengalaman berupa skill menyaring air kotor menjadi air bersih.

Luaran lain yang dicapai dari proses pengabdian perancangan desain saringan air lambat ini ialah telah diterbitkannya sertifikat hak cipta panduan saringan air lambat oleh Kemenkumham RI dengan nomor permohonan dan tanggal permohonan EC00202015864, 20 Mei 2020 dengan masa berlaku seumur hidup pencipta.

\section{KESIMPULAN DAN SARAN}

\section{Kesimpulan}

Berdasarkan hasil dan pembahasan, diperoleh simpulan bahwa terciptanya desain saringan air lambat menggunakan pasir kerubung merupakan suatu solusi untuk menyaring air di Pondok Pesantren Tarbiyah Islamiyah (PPTI). Desain yang dibuat merupakan komponen penyaringan menggunakan bahan-bahan lokal dan khas daerah pesisir pantai Kota Singkawang.

\section{Saran}

Dikarenakan uji klinis masih terbatas pada variable tertentu, maka disarankan agar uji klinis diperluas pada variable lain sehingga kemanfaatn hasil saringan dapat menjadi lebih dalam. Selain itu, desain saringan air masih dalam skala kecil sehingga diperlukan desain dengan proporsi yang lebih bagus untuk skala pengguna yang lebih besar misalnya untuk saringan air di tempat ibadah dan sejenisnya.

\section{UCAPAN TERIMA KASIH}

Tim pengabdi mengucapkan terimakasih kepada DRPM Kemenristek-BRIN atas Hibah PKM DRPM Ristek-BRIN No.Kontrak 429/L11/KM/2020 sehingga program PKM ini dapat terselenggara sesuai dengan waktu yang telah direncanakan.

\section{DAFTAR PUSTAKA}

Andrie, A., Fatmawati, S., \& Tehuayo, H. (2016). Rancangan Sistem Penjernihan Air Baku Dengan Sistem Slow Sand Filter Di Desa Lekopancing Kab. Maros Sulawesi Selatan. ILTEK: Jurnal Teknologi, 11(01), 1523-1530. https://doi.org/10.47398/iltek.v11i01.123

Fatma, F. (2018). Kombinasi Saringan Pasir Lambat Dalam Penurunan Kadar Fe (Besi) Air Sumur Gali Masyarakat di Wilayah Kerja Puskesmas Lasi kabupaten Agam. Menara Ilmu, XII(7), 3540.

Handarsari, E., Hidayah, F. F., Studi, P., Universitas, G., Semarang, M., Kimia, P., Muhammadiyah, U., Studi, P., Universitas, G., \& Semarang, M. (2017). Deseminasi : Pembuatan Air Bersih Dengan Memanfaatkan Air Hujan Melalui Penyaring Pipa Bersusun Berbasis Adsorben. Prosiding Seminar Nasional Publikasi Hasil-Hasil Penelitian Dan Pengabdian Pada 
Masyarakat, September, 496-503.

Istiqomah, A. (2014). Pengaruh Kombinasi Ketebalan Media Filter Pasir dan Zeolit Terhadap Penurunan Kadar Kesadahan Pada Air Sumur di Desa Kismoyo Ngemplak Boyolali.

Kristianto, H., Katherine, K., Soetedjo, J. N. M., Pratiwi, F., Handriono, C. W., Guntoro, V. J., Farand, R. J., Suhendar, B. Y., \& Mulyana, Y. (2017). Penyediaan Air Bersih Masyarakat Sekitar Masjid Al-Iklas Desa Cukanggenteng Ciwidey dengan Menggunakan Penyaringan Air Sederhana. Jurnal Pengabdian Kepada Masyarakat (Indonesian Journal of Community Engagement), 3(1), 39-49. https://doi.org/10.22146/jpkm.28148

Kusumawardani, Y., \& Astuti, W. (2019). Efektifitas Penambahan Media Geotekstil Pada Saringan Pasir Lambat Terhadap Penyisihan Parameter Kekeruhan, Jumlah Coli Dan Cod. Jurnal Teknosains, 8(2), 114. https://doi.org/10.22146/teknosains.31917

Makmudah, N., \& Notodarmojo, S. (2010). Penyisihan Besi-Mangan, Kekeruhan dan Warna Menggunakan SaringanPasir Lambat Dua Tingkat Pada Kondisi Aliran Tak Jenuh. Studi KAsus: Air Sungai Cikapundung. Jurnal Teknik Lingkungan, 16(2), 150-159.

Nainggolan, A. H., Mulia Tarigan, A. P., \& Khair, H. (2017). Pengaruh Aerasi Bertingkat dengan Kombinasi Saringan Pasir, Karbon Aktif, dan Zeolit dalam Menyisihkan Parameter Fe dan Mn dari Air Tanah di Pesantren Ar-Raudhatul Hasanah. Jurnal Teknik, 143(1), 1-12.

Quddus, R. (2104). Teknik Pengolahan Air Bersih dengan Sistem Saringan PAsir Lambat (Downflow) yang bersumber dari Sungai Musi. Jurnal Teknik Sipil Dan Lingkungan, 2(4), 669-675. http://www.ghbook.ir/index.php?name= مجموعه مقالات دومين هم انديشى سراسرى رسانه تلويزيون و سكو لاريسم/option=com_dbook\&task=readonline\&book_id=13629\&page=108\&chkhashk=03C70 6812F\&Itemid $=218 \&$ lang $=$ fa\&tmpl=component

Salim, N., Rizal, N. S., \& Vihantara, R. (2018). Komposisi Efektif Batok Kelapa sebagai Karbon Aktif untuk Meningkatkan Kualitas Airtanah di Kawasan Perkotaan. Media Komunikasi Teknik Sipil, 24(1), 87-95. https://doi.org/mkts.v24i1.18865

Sampurno, P. J., Sari, Y. A., \& Wijaya, A. D. (2015). Integrating STEM (Science, Technology, Engineering, Mathematics) and Disaster (STEM-D) Education for Building Students' Disaster Literacy. International Journal of Learning and Teaching, 1(1), 73-76. https://doi.org/10.18178/ijlt.1.1.73-76

Sugiarto, B., \& Suharwanto. (2017). Pengembangan Pemanfaatan Pengolahan Air Dalam Upaya Pemenuhan Kebutuhan Air di Dusun Temuireng, Desa Girisuko, Panggang, Gunungkidul Developing the Utilization of Water Treatment Technology to Fill Water Demand at TemuirengGirisuko Village ,. Eksergi, 14(2), 40-52.

Sumekar, A., \& Febriani, H. (2019). Demontrasi Penyaringan Air Sederhana. Dimas: Jurnal Pengabdian Masyarakat, 1(2), 49-52. https://jurnal.stikeswirahusada.ac.id/dimas 